\title{
An Empirical Study of the Relationships between Different Types of Innovation and Firm Performance
}

\author{
Shouyu Chen \\ Zhejiang Yuexiu University of Foreign Languages, Shaoxing, P.R.China \\ chenshyu@zju.edu.cn
}

Keywords: Innovation types; Firm performance; SME; Textile industry

\begin{abstract}
Divided into different types of innovation's influence on firm performance can be further understanding of the relationships between innovation and firm performance. By building a theoretical model of the relationship between different types of innovation and enterprise performance, collecting the survey data of 203 small and medium-sized textile enterprises, and applying structural equation model to test the model, the results provided that under the background of different types of innovation including product innovation, process innovation, marketing innovation and Organizational innovation, product innovation played a central role, and Organizational innovation played a basic role in the relationships between innovation and firm performance. Product innovation played a full mediating effect in both process innovation and Organizational innovation influencing on enterprise performance. Product innovation played a partial mediation effect in marketing innovation influencing on enterprise performance. Organizational innovation had a significant impact on product innovation, process innovation and marketing innovation, thus indirectly affecting enterprise performance.
\end{abstract}

\section{Introduction}

There is a very complex relation between innovation and business performance, although have a lot of related research literature, but the relations have not been fully tested [1]. Based on the practice of innovation survey, the enterprise innovation activities are divided into four categories-product innovation, process innovation, marketing innovation and Organizational innovation [2]. Because the object and the content of the different types of innovation activities may not be the same, the impact on enterprise performance may also be different [3]. Therefore, there is likely to be more meaningful that we distinguish among different types of innovation influence on enterprise performance. In addition, different types of innovation are influence and complement each other, and take the both of the management of innovation and technology innovation can more maintain or improve enterprise performance than one type innovation alone. Exploring between these four types of innovation and its relationship with corporate performance will further provide the internal mechanism of the relationship between innovation and enterprise performance. This paper will put forward hypothesis of different types of innovation effect on corporate performance, and then effect on corporate performance. Finally, Structural Equation Model (SEM) is used to test these hypotheses.

\section{Hypothesis}

The research of the relationship between innovation and enterprise performance in the current literatures is more, while the research of the relationship between different types of innovation and business performance is rarely [4]. Due to the differences in the content of different types of innovation, leads to the different types of innovation can have different impacts on enterprise performance.

H1: Product innovation has a significant effect on corporate performance.

$\mathrm{H} 2$ : Product innovation has a significant effect on corporate performance.

H3: Marketing innovation has a significant effect on corporate performance.

H4: Organizational innovation has a significant effect on corporate performance. 
In addition to the real survey need, also considering the interaction between different innovation type, especially implementation of organizational change in order to benefit the other types of innovation, OECD distinguishes innovation in four areas: product, process, marketing and organizational. Product and process innovations are familiar concepts in the business sector, and were the sole focus of the previous editions of the Oslo Manual, in which organizational changes were covered in an annex and marketing innovations were not addressed. Both organizational and marketing innovations are extensively discussed in the third edition.

Many studies have found that organizational innovation in enterprise leaded to the improvement of the organization structure and management and then helped for other types of innovation. For instance, Walker announced that organizational, marketing and service (or product) innovations were found to be interrelated in a study on public organizations, and that additional research was required to clarify these findings [5].

Considering the existing theoretical and empirical literature, we argue that organizational innovations -namely the implementation of a new organizational method in the firm's business practices, workplace organization or external relations- would greatly promote the enterprise external information acquisition and cooperation, and internal employee satisfaction and then create suitable internal and external environment for other types of innovation. Therefore, we hypothesize that:

H5 (H6\H7): Organizational innovation has a significant effect on product (process $\$ marketing) innovation.

Because these hypotheses of different types of innovation impact on enterprise performance have been proposed above, therefore we can hypothesize:

H8 (H9\H10): The product (processlmarketing) innovation plays a mediation effect in the relationship between organizational innovation and business performance.

$\mathrm{Li}$, Liu and Ren found significant correlation between technological innovation and product innovation according to the study of China's state-owned enterprises [6], and based on British service enterprise research, Oke suggested that it is necessary to develop a formal implementation process for the pursuit of progressive product or service innovation, and emphasized that process improvement was the driving force of success for a product or service innovation [7]. Process innovation brings the improvement of production process, thus the product quality, value, speed and low cost advantage, in order to better meet customer needs and desires. Therefore, we hypothesize that:

H11: Process innovation has a significant effect on product innovation;

H12: The product innovation plays a mediation effect in the relationship between process innovation and business performance.

OECD suggested these would be very important to the success of new products if a large number of resources were used for market research and development of new marketing strategy. Many literatures emphasized the importance of correct market introduction, especially should attach great importance to communication with the market and timely market information when new products were introduced to the market [8]. In addition, marketing innovation-the product concept testing, providing additional services, increasing the distribution channels, new advertising and promotion-also affected the success or failure of new product. There should be a mutual support relationship between marketing innovation and product innovation, product innovations were affected by the market and the customer's expectations, while the customer's expectations will be done by marketing innovation, which implies marketing innovation affects product innovation. Therefore, we hypothesize that:

H13: Marketing innovation has a significant effect on product innovation;

H14: The product innovation plays a mediation effect in the relationship between marketing innovation and business performance. 


\section{Data}

In the similar studies, according to different research purposes the researchers usually collect first-hand data. The main data collection methods include interview and questionnaire method. In this study, we also will conduct enterprises interview and questionnaire survey to obtain relevant data. According to the basis and conditions of this study, we will collect the data mainly in Shaoxing small and medium-sized textile enterprises, the reason mainly has the following points: first, there may be exist the technical heterogeneity among different industries, we can eliminate the influence of the heterogeneity to choose the single textile industry ; second, we selected the textile industry because of the importance of the industry itself, including understanding the textile industry innovation in the dramatic change of domestic and foreign environment can help enterprises to better innovation; third, the small and medium-sized textile enterprises are numerous, these companies are not only attaches importance to technical (products or process) innovation, but also pay attention to management (marketing or organizational) innovation, such as small and medium-sized enterprises develop new products, improve old products, change production process and logistics way, expand the market and create brand through marketing innovation, and along with the variety of products and scale resulting in organization structure, management processes and organizational innovation, therefore the innovation practice of small and medium-sized textile enterprises can better meet our requirements for different types of innovation. Questionnaires were distributed in two ways: first, the copies of 20 questionnaires handed out at the scene of the enterprise by researchers; second, the copies of 525 questionnaires handed out by the researchers' students. The former the valid response rate is $100 \%$, the latter is $92.76 \%$. This investigation altogether provides questionnaire 545, the actual recovery of 507 copies, of which 203 valid questionnaires, for an effective questionnaire returns-ratio is $40 \%$.

\section{Method}

According to the theoretical assumptions, we can draw the initial SEM path graph (Fig. 1).

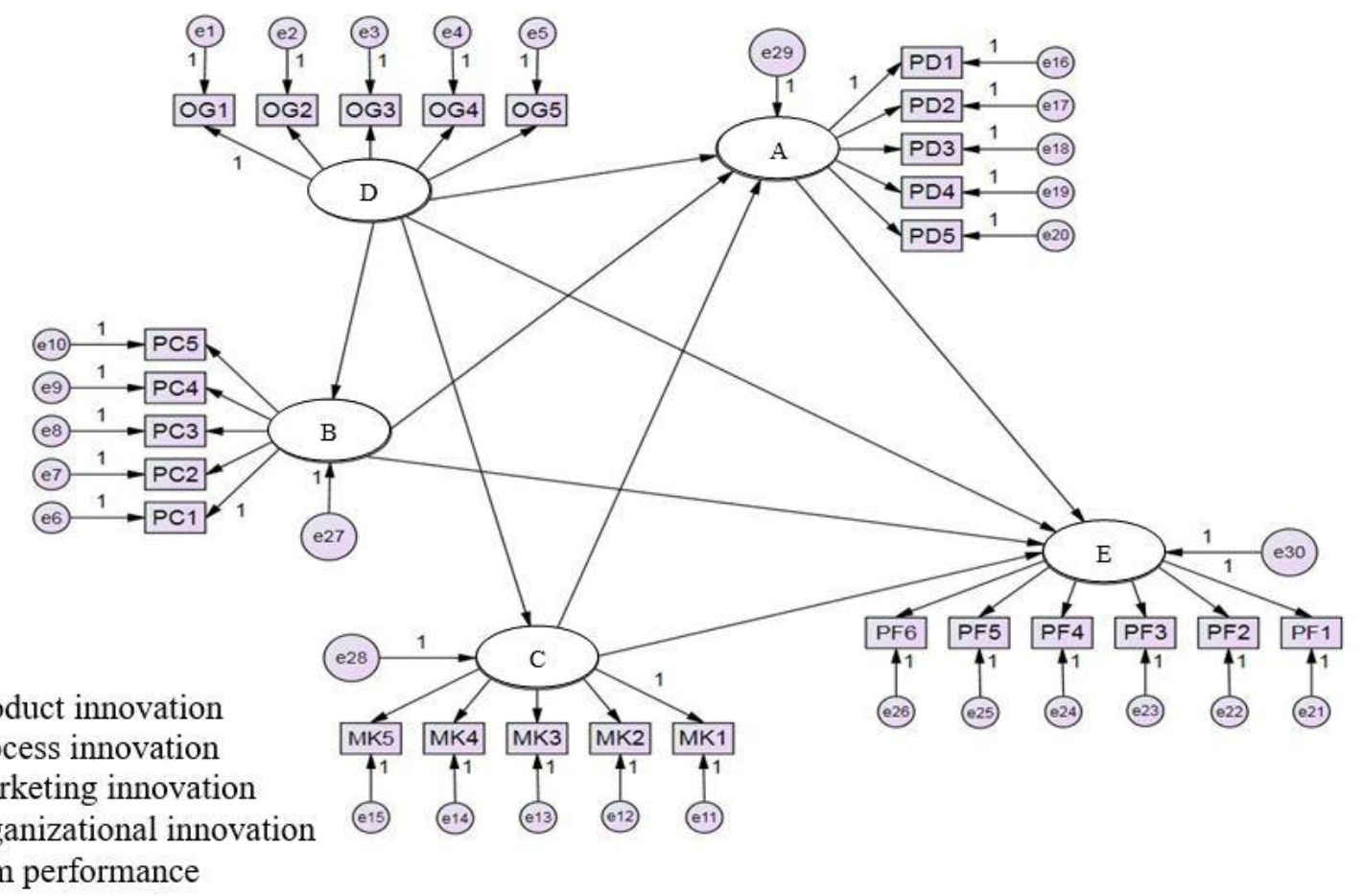

Figure 1. The initial SEM path graph

According to the revised SEM model fitting degree index, the revised model fitting degree is 
good. At the same time, the AMOS software also output the parameter estimation of the revised SEM model (Table 1).

Table 1. The parameter estimation of the revised SEM model

\begin{tabular}{|c|c|c|c|c|c|}
\hline Path & $\begin{array}{c}\text { Estimated } \\
\text { Value }\end{array}$ & $\begin{array}{c}\text { Standardized } \\
\text { Estimate }\end{array}$ & SE & C.R. & P \\
\hline $\begin{array}{c}\text { process innovation } \leftarrow \\
\text { organizational innovation }\end{array}$ & .346 & .720 & .080 & 4.325 & $* * *$ \\
\hline $\begin{array}{c}\text { marketing innovation } \\
\text { organizational innovation }\end{array}$ & .154 & .475 & .054 & 2.862 & .004 \\
\hline $\begin{array}{c}\text { product innovation } \leftarrow \\
\text { organizational innovation }\end{array}$ & .126 & .415 & .053 & 2.396 & .017 \\
\hline $\begin{array}{c}\text { product innovation } \leftarrow \\
\text { process innovation }\end{array}$ & .211 & .333 & .103 & 2.046 & .041 \\
\hline $\begin{array}{c}\text { product innovation } \leftarrow \\
\text { marketing innovation }\end{array}$ & .433 & .461 & .170 & 2.551 & .011 \\
\hline $\begin{array}{c}\text { firm performance } \leftarrow \\
\text { organizational innovation }\end{array}$ & .033 & .031 & .106 & .316 & .752 \\
\hline $\begin{array}{c}\text { firm performance } \\
\text { process innovation }\end{array}$ & .067 & .030 & .207 & .323 & .747 \\
\hline $\begin{array}{c}\text { firm performance } \leftarrow \\
\text { marketing innovation }\end{array}$ & .992 & .298 & .407 & 2.437 & .015 \\
\hline $\begin{array}{c}\text { firm performance } \\
\text { product innovation }\end{array}$ & .991 & .280 & .465 & 2.131 & .033 \\
\hline ***P value <0.001 & & & & \\
\hline
\end{tabular}

\section{Result}

From Table 1, the estimate of standardized path coefficient of the product innovation affecting enterprise performance is 0.280 ; this path coefficient is significant under 0.05 significant level. The results show that the product innovation has obvious positive correlation to the enterprise performance; the enterprise's product innovation helps to achieve the goals of enterprise performance, and hypothesis $\mathrm{H} 1$ cannot be refused. The estimate of standardized path coefficient of the process innovation affecting enterprise performance is 0.030 ; this path coefficient is not significant under 0.05 significant level. The results show that the process innovation has not obvious correlation to the enterprise performance and hypothesis $\mathrm{H} 2$ can be refused. The estimate of standardized path coefficient of the marketing innovation affecting enterprise performance is 0.298; this path coefficient is significant under 0.05 significant level. The results show that the marketing innovation has obvious positive correlation to the enterprise performance; the enterprise's marketing innovation helps to achieve the goals of enterprise performance, and hypothesis H3 cannot be refused. The estimate of standardized path coefficient of the organizational innovation affecting enterprise performance is 0.031 ; this path coefficient is not significant under 0.05 significant level. The results show that the organizational innovation has not obvious correlation to the enterprise performance and hypothesis $\mathrm{H} 4$ can be refused.

From Table 1, the estimate of standardized path coefficient of the organizational innovation affecting product innovation is 0.415 ; this path coefficient is significant under 0.05 significant level. The results show that the organizational innovation has obvious positive correlation to product innovation, the enterprise's organizational innovation helps to achieve product innovation, and hypothesis $\mathrm{H} 5$ cannot be refused. The same method can verify that H6, H7 cannot be refused.

The estimate of standardized path coefficient of the process innovation affecting product innovation is 0.333 ; this path coefficient is significant under 0.05 significant level. The results show that the process innovation has obvious positive correlation to product innovation, the enterprise's process innovation helps to achieve product innovation, and hypothesis $\mathrm{H} 11$ cannot be refused. The same method can verify that H13 cannot be refused. 
From Table 1, the path coefficient of the organizational innovation affecting enterprise performance is not significant and organizational innovation influence on enterprise performance through the mediation effect of product innovation, process innovation and marketing innovation. Therefore, H8, H9, H10 have been supported.

The path coefficient of the process innovation affecting enterprise performance is not significant and process innovation influence on enterprise performance through the mediation effect of product innovation. Therefore, $\mathrm{H} 12$ has been supported.

The unstandardized path coefficient of the marketing innovation affecting enterprise performance is significant, and this path coefficient is 0.992. At the same time, the marketing innovation through the mediation effect of product innovation, indirectly effects on enterprise performance. The results show that marketing innovation influence on enterprise performance includes both direct and indirect effect by product innovation's mediation role and product innovation played only a partial mediation. Therefore, H14 has been supported.

\section{Conclusion}

In the four different types of innovation, organizational innovation has played a fundamental role, it promoted the product innovation, process innovation and marketing innovation, organization innovation affect enterprise performance through the other three types of innovation. Product innovation has played a central role for the other three kinds of innovation to achieve their enterprise performance, process innovation, marketing innovation and organizational innovation having the impact on enterprise performance were achieved by product innovation either in part or in whole. Process innovation on the one hand, is influenced by organizational innovation; on the other hand, through product innovation indirectly affect enterprise performance. Marketing innovation on the one hand, is influenced by organizational innovation; on the other hand, both directly affect enterprise performance and through product innovation indirectly affect enterprise performance. According to the above conclusion, we suggest that the small and medium-sized enterprises in innovation activity should emphasize the basis role of organizational innovation and the central role of product innovation, through the synergy of different kinds of innovation to achieve higher enterprise performance. Due to the limitations of the research sample, these inclusions applied to general small and medium-sized enterprises, should be further discussed.

\section{References}

[1] N. Capon, J. U. Farley and D. R. Lehmann: Management Science, Vol.38 (1992) No.2, p. 157-169.

[2] OECD: The Measurement of Scientific and Technological Activities, Oslo Manual: Guidelines for Collecting and Interpreting Innovation Data (Organization for Economic Co-operation and Development, 2005).

[3] A. Oke, G. Burke, A. Myers: International Journal of Operations \& Production Management, Vol.27 (2007) No.7, p.735-753.

[4] Z. Jin, N. Hewitt-Dundas, N. J. Thompson: Journal of Strategic Marketing, Vol.12 (2004) No.4, p. 255-266.

[5] R. Walker: Advanced Institute of Management Research Paper, 2004, Vol.2 (2004).

[6] Y. Li, Y. Liu and F. Ren: The Journal of Technology Transfer, Vol.32 (2007) No.1, p.63-85.

[7] A. Oke: International Journal of Operations \& Production Management, Vol.27 (2007) No.6, p.564-587.

[8] W. E. Souder, X. M. Song: Journal of Product Innovation Management, Vol.14 (1997) No.1, p.21-34. 